\title{
Efficient Fractionation of Corn Stover by Bisulfite Pretreatment for the Production of Bioethanol and High Value Products
}

\author{
Liping Tan, a,b,* Zhongyang Liu, ${ }^{\mathrm{b}}$ Tongjun Liu, a,b,* and Fangfang Wang a \\ Fractionation of corn stover (CS) was carried out by bisulfite pretreatment \\ in order to improve the production of bioethanol and high-value chemicals. \\ Firstly, the optimum bisulfite pretreatment conditions of CS $\left(170{ }^{\circ} \mathrm{C}, 30\right.$ \\ min, $7 \% \mathrm{NaHSO}_{3}, 1 \% \mathrm{H}_{2} \mathrm{SO}_{4}$ ) were identified. Next, a biorefinery process \\ of bisulfite pretreatment for CS was proposed. CS was separated into solid \\ and liquor components using such pretreatment. The solid components \\ were employed for bioethanol production by quasi-simultaneous \\ saccharification and fermentation (Q-SSF). The bisulfite liquor was \\ fractionated into hemicellulosic sugars and lignin by different types of \\ resins. It was shown that CS components could be effectively fractionated \\ through bisulfite pretreatment in combination with resin separation to \\ produce bioethanol, hemicellulosic sugars, and lignosulfonate.
}

Keywords: Corn stover; Bioethanol; Bisulfite pretreatment; Lignosulfonate; Biorefinery

Contact information: a: State Key Laboratory of Biobased Material and Green Papermaking, Qilu University of Technology, Shandong Academy of Sciences, Jinan, 250353, China; $b$ : Shandong Provincial Key Laboratory of Microbial Engineering, Department of Bioengineering, Qilu University of Technology, Shandong Academy of Sciences, Jinan, 250353, China; *Corresponding author: Liping Tan, tanliping163@163.com; Tongjun Liu, liutongjun@outlook.com.

\section{INTRODUCTION}

Lignocellulosic biofuels are recognized as a potential alternative to fossil fuels (Ho et al. 2019; Milano et al. 2016). Many studies have been conducted to develop efficient technologies to convert lignocellulosic polysaccharides to bioethanol (Alvira et al. 2010). Corn stover (CS) is one of the most promising lignocellulosic biomasses for bioethanol production (Zabed et al. 2016). CS (the leaves, stalks, and husk left over after corn is harvested) is composed of high contents of cellulose and hemicellulose, and much attention has been paid to CS due to its low-cost in production of bioethanol and other by-products (Kadam et al. 2008; Buruiana et al. 2014; Uppugundla et al. 2014).

Unlike starch-based ethanol, the major problem in producing lignocellulosic bioethanol is that CS has a low conversion due to the recalcitrance of the material (Zhao et al. 2012; Meng et al. 2016). Biomass recalcitrance is thought to largely arise due to the spatial network of cellulose, hemicellulose, and lignin as a protective bulwark that restricts enzyme accessibility (Zhang et al. 2011). Several pretreatment processes have been developed to overcome biomass recalcitrance, such as dilute acid pretreatment (Liu et al. 2016), steam explosion pretreatment (Liu et al. 2013), organic acid pretreatment (Huang et al. 2018), hot water pretreatment (Li et al. 2014; Li et al. 2015), ammonia fiber expansion pretreatment (AFEX) (Kumar et al. 2009; Sundaram et al. 2015), and ionic liquid (IL) pretreatment (Papa et al. 2017). However, different pretreatments present 
various challenges due to the costs generated by using expensive chemicals, water, chemical recovery, energy, and the needed equipment (Brodeur et al. 2011).

Previous work has shown that bisulfite pretreatment is a promising process that can be used in the effective conversion of different lignocellulose polysaccharides into bioethanol as a liquid fuel source (Zhu et al. 2009; Tan et al. 2013; Li et al. 2014; Liu et al. 2017). Wang et al. (2011) and Yu et al. (2015) showed that the enzymatic hydrolysis of CS for ethanol production can be significantly improved using bisulfite pretreatment. However, to date, there has been a lack of studies exploring the biorefinery of CS using bisulfite pretreatment. In biorefinery, all the major components of CS (including cellulose, hemicellulose, and lignin) should be fractionated to liquid fuels and other high-value products. Significant hemicellulose degradation and sulfonation of lignin occur during bisulfite pretreatment (Tan et al. 2016), which improves the enzymatic digestibility of pretreated lignocellulosic solids. However, only part of the xylan and sulfonated lignin are spontaneously dissolved into the spent liquor, leading to the waste of these components. Therefore, the spent liquor is considered as a feedstock to produce high-value chemicals, such as xylose, xylan, and lignosulfonate, by which the biorefinery of CS can be realized. Furthermore, industrial-scale technology is in the early stage of development (Aditiya et al. 2016; Chen and Fu 2016), and pretreatment process and overall technological facilities are still under investigation in producing bioethanol from CS. Bisulfite pretreatment is derived from the traditional sulfite pulping process (Zhu et al. 2009), which has been performed in industry practice for more than a century. As a mature technology, the use of bisulfite pretreatment has a great advantage because the equipment and infrastructure for bisulfite pretreatment process have been widely used in the pulp and paper industries, which may greatly accelerate the process of industrial studies and the technologies for bioethanol production from CS and other lignocellulosic biomasses.

The present study aimed to separate cellulose, hemicellulose, and lignin from CS using the bisulfite pretreatment. Firstly, bisulfite pretreatment was applied on CS based on the chemical components of CS. Secondly, cellulose could be transformed into bioethanol through the quasi-simultaneous saccharification and fermentation (Q-SSF) process. Finally, different types of resins were employed to separate hemicellulose and lignin in the spent liquor in order to produce potential products, such as hemicellulosic sugars and lignosulfonate.

\section{EXPERIMENTAL}

\section{Materials}

CS was purchased from Weifang, Shandong Province, P. R. China. The processed CS was air-dried until constant moisture content was achieved (about 10\%). Dried CS was cut to small pieces of 2-3 cm in length, sealed in bags, and then stored at room temperature.

Cellic ${ }^{\circ}$ CTec 2 was obtained from the commercially available source (Novozymes). The filter paper activity was determined to be $100 \mathrm{FPU} / \mathrm{mL}$. Sodium bisulfite, sulfuric acid, and ethanol were of analytical grade. Other reagents, such as D(+)glucose, D-(+)xylose, furfural, and 5-hydroxy-2-furaldehyde (HMF), were of chromatographic grade. Macroporous adsorption resins AB-8, DM130, CAD-40, and DM301 were provided by Hecheng New Material Co., Ltd., Zhengzhou, China. 


\section{Bisulfite Pretreatment of CS}

Bisulfite pretreatment was carried out in a rotary electrothermal pressure digester (ZQS-3, Qinggong Jixie Factory of Shanaxi University of Science and Technology, Xianyang, Shaanxi Province, P. R. China) as follows. The reaction was performed at 170 ${ }^{\circ} \mathrm{C}$ for 30 min in a solution of sodium bisulfite consisting of 3\%, 4\%, 7\%, or $8 \% \mathrm{NaHSO}_{3}$ and $1 \% \mathrm{H}_{2} \mathrm{SO}_{4}$ (based on weight of dry CS, w/w). The reaction pressure was about 0.7 to $0.8 \mathrm{MPa}$. The ratio of CS (dry weight, g) to liquor (volume, mL) was 1:4. Subsequently, the insoluble solids were filtered using bag-type strainer and reserved for subsequent analyses.

\section{Enzymatic Hydrolysis}

The CS and the pretreated samples were hydrolyzed by Cellic $®$ CTec 2 in $100-\mathrm{mL}$ flasks to evaluate their enzymatic digestibility under following conditions: $2 \%$ solid concentration (dry matter basis), $\mathrm{pH}$ of 4.8 (0.05 M sodium acetate buffer), $48^{\circ} \mathrm{C}, 150 \mathrm{rpm}$ in a shaker, and cellulase dosage of $10 \mathrm{FPU} / \mathrm{g}$ dry sample. The supernatant was used to determine the contents of glucose and xylose by the high-performance liquid chromatography (HPLC, Shimadzu, Japan) equipped with a refractive index detector (Shimadzu) on an Aminex HPX-87H column (Bio-Rad, USA). Briefly, $5 \mathrm{mM} \mathrm{H}_{2} \mathrm{SO}_{4}$ was employed as eluent at a flow rate of $0.6 \mathrm{~mL} / \mathrm{min}$, and the column temperature was maintained at $65{ }^{\circ} \mathrm{C}$. The conversions of cellulose and xylan in enzymatic hydrolysis process were calculated using the equations as follows:

Conversion of cellulose(\%)

$$
=\frac{\text { Gluose released from enzymatic hydrolysis }(\mathrm{mg}) \times 0.9}{\text { Sample weight }(\mathrm{mg}) \times \text { Glucan content }(\%)} \times 100 \%
$$

Conversion of xylan(\%)

$$
=\frac{\text { Xylose released from enzymatic hydrolysis }(\mathrm{mg}) \times 0.88}{\text { Sample weight }(\mathrm{mg}) \times \text { Xylan content }(\%)} \times 100 \%
$$

\section{Q-SSF}

The Q-SSF experiment was performed in 100-mL anaerobic bottles using a commercial yeast strain of Saccharomyces cerevisiae (Angel Yeast Corporation Ltd., Hubei, China) according to the authors' previous work (Tan et al. 2013). Briefly, approximately $0.22 \mathrm{~g}$ of yeast was first activated. Subsequently, fermentation was carried out with $0.45 \mathrm{~g}$ glucose and $10 \mathrm{~mL}$ sterile water at $30{ }^{\circ} \mathrm{C}$ and $200 \mathrm{rpm}$ for $2 \mathrm{~h}$. The solid concentration of Q-SSF was $15 \%$. The Q-SSF process consisted of pre-hydrolysis and subsequent fermentation process. Cellic ${ }^{\circledR}$ CTec2 (cellulase loading of 10 FPU/g dry solid sample) was added in the pre-hydrolysis phase, followed by incubation for $6 \mathrm{~h}$. Next, the activated yeast (5 mg yeast/g dry sample) was supplemented into the fermentation for QSSF. The ethanol content was determined using the HPLC equipped with a refractive index detector (Shimadzu) on an Aminex HPX-87H column (Bio-Rad, USA). Briefly, $5 \mathrm{mM}$ $\mathrm{H}_{2} \mathrm{SO}_{4}$ was employed as eluent at a flow rate of $0.6 \mathrm{~mL} / \mathrm{min}$, and the column temperature was maintained at $65{ }^{\circ} \mathrm{C}$. The cellulose conversion in Q-SSF process was calculated as follows (Dowe and McMillan 2008),

$$
\text { Cellulose conversion }(\%)=\frac{[\mathrm{EtOH}]}{f \times \text { biomass } \times 1.11 \times 0.51} \times 100 \%
$$


where $[\mathrm{EtOH}]$ is the ethanol concentration at the end of the fermentation $(\mathrm{g} / \mathrm{L})$, biomass is the dry biomass concentration at the beginning of the fermentation $(\mathrm{g} / \mathrm{L}), f$ is the cellulose fraction in dry biomass $(\mathrm{g} / \mathrm{g}), 0.51$ is the conversion factor for glucose to ethanol based on stoichiometric biochemistry of yeast, and 1.11 is the conversion factor for cellulose to the equivalent glucose

\section{Resin Separation for Fractionation of Spent Bisulfite Pretreatment Liquid}

In the present study, the hemicellulose and lignin constituents in the spent liquid were separated using various macroporous adsorption resins, such as AB-8, DM130, CAD40, and DM301. Table 1 lists the physical properties of the four resins. Briefly, the impurities and monomers inside the pores of resins were removed by pretreating the resins with $\mathrm{NaOH}$ and $\mathrm{HCl}$ solutions. Subsequently, all resins were washed with deionized water. A chromatographic column $(50 \mathrm{~cm}$ in length and $1.5 \mathrm{~cm}$ in diameter) was filled with different types of resin. The spent bisulfite pretreatment liquor was loaded onto the column at a constant speed, and then the column was washed with five volumes of deionized water. The filtered liquid (mainly consisting of sugars, named as carbohydrate constituent, CCS) was collected, and its chemical compositions were determined. The chromatographic column was then eluted with five volumes of $95 \%$ methanol, and all the eluent (mainly consisting of the lignosulfonate, named as lignosulfonate constituent, LCS) was pooled and analyzed. The recovery efficiencies of reducing sugar and lignosulfonate in CCS and LCS from different resins were determined, which were expressed as a proportion of the substance content in CCS or LCS to that in spent pretreatment liquor.

The eluent was dried to lignosulfonate solids (LSS) by vacuum distillation, followed by structural and property analyses. The spent bisulfite pretreatment liquid was vacuum freeze-dried to obtain control sample, which was designated as water-soluble substance (WSS) and directly compared with LSS. Above-mentioned experiment was carried out at least in duplicate, and the results were expressed as the means of repeated experiments.

Table 1. The Physical Properties of Four Macroporous Resins

\begin{tabular}{|c|c|c|c|c|}
\hline Macroporous Resin & AB-8 & DM301 & DM130 & CAD-40 \\
\hline Structure & Polystyrene & Polystyrene & Polystyrene & Polystyrene \\
\hline Micropore area $\left(\mathrm{m}^{2} / \mathrm{g}\right)$ & $480-520$ & $330-380$ & $500-550$ & $450-500$ \\
\hline Micropore volume $(\mathrm{ml} / \mathrm{g})$ & $0.73-0.77$ & $0.7-0.9$ & $0.81-0.88$ & $0.73-0.77$ \\
\hline Pore diameter $(\mathrm{nm})$ & $13-14$ & $14-17$ & $9-10$ & $5-6$ \\
\hline Polarity & Weak polar & Moderate polar & Weak polar & Weak polar \\
\hline
\end{tabular}

\section{WSS and LSS Analyses}

The contents of $\mathrm{C}, \mathrm{H}, \mathrm{N}$, and $\mathrm{S}$ were determined by elemental analyses of LSS and WSS (Vario EL III, Germany). Fourier transform infrared spectroscopy (FT-IR) (ALPHA, Germany) was employed to analyze the FT-IR spectra of the LSS and WSS samples using $\mathrm{KBr}$ discs.

\section{Analytical Methods}

The contents of cellulose (glucan), xylan, and lignin in untreated and pretreated CS samples were assessed according to NREL methods (Sluiter et al. 2008). The acid-soluble lignin was determined by UV-vis spectroscopy at a wavelength of $320 \mathrm{~nm}$ with an 
absorptivity of 30 (L/g cm). An Aminex HPX-87H column (Bio-Rad, USA) was used to separate furfural and 5-HMF (Loow et al. 2018). Briefly, $5 \mathrm{mM} \mathrm{H}_{2} \mathrm{SO}_{4}$ was employed as eluent at a flow rate of $0.5 \mathrm{~mL} / \mathrm{min}$, and the column temperature was maintained at $40{ }^{\circ} \mathrm{C}$. A UV-vis spectrophotometer (UV-5500PC, METASH, China) with a typical absorption peak at $280 \mathrm{~nm}$ was used to determine the lignosulfonate content in the spent liquor (Li et al. 2012). The content of reducing sugar in bisulfite pretreatment liquid was examined by the 3,5-dinitrosalicylic acid (DNS) colorimetric method (Breuil and Saddler 1985).

\section{RESULTS AND DISCUSSION}

\section{Bisulfite Pretreatment of CS}

Previous studies have shown that bisulfite pretreatment is an efficient pretreatment, exhibiting great enzymatic cellulose conversion and ethanol production (Tan et al. 2013; Tian et al. 2011; Wang et al. 2011). In the present study, such a process was selected for the CS pretreatment, after which CS was separated into the cellulosic solids and spent liquor.

It has been found that $\mathrm{NaHSO}_{3}$ dosage and $\mathrm{H}_{2} \mathrm{SO}_{4}$ dosage are the important factors affecting the bisulfite pretreatment (Tan et al. 2016). Previous studies have shown that $1 \%$ acid almost completely removes the xylan in the raw material (Tan et al. 2013; Wang et al. 2011). Therefore, the effect of $\mathrm{NaHSO}_{3}$ dosage was investigated relative to bisulfite pretreatment of CS. The major composition changes of CS upon bisulfite pretreatment were analyzed with different $\mathrm{NaHSO}_{3}$ dosages $(3 \%, 4 \%, 7 \%$, or $8 \%)$ and $1 \%$ acid at $170{ }^{\circ} \mathrm{C}$ for $30 \mathrm{~min}$, and Table 2 lists the results.

The contents of cellulose, hemicellulose, and lignin in untreated CS were about $27 \%, 13 \%$, and 20\%, respectively. As shown in Table 2, the contents of extractives in the bisulfate-pretreated CS (about 9 to 10\%) were significantly increased compared with the untreated samples $(2.29 \%)$. Acidification appeared to be the main reason for the precipitation of extractives on the substance surfaces (Koljonen et al. 2004). Some ligninderivatives might be precipitated from the pretreatment liquid and adsorbed on the substance surfaces (Dai et al. 2006), leading to the increased extractives in the bisulfitepretreated samples. Moreover, the hemicellulose content of the solid substrates was increased with the decrease of $\mathrm{NaHSO}_{3}$ dosage. More xylan was dissolved at higher $\mathrm{NaHSO}_{3}$ dosage.

When $\mathrm{NaHSO}_{3}$ dosage was increased from $3 \%$ to $8 \%$, the solubility of xylan was increased from $66.19 \%$ to $75.8 \%$, indicating that a large portion of hemicelluloses was removed during bisulfite pretreatment. Previous study has demonstrated that hemicelluloses can be removed through the cleavage of glycosidic ether linkages between sugar units during bisulfite pretreatment (Tan et al. 2015). The degree of delignification was increased from $17.9 \%$ to $39.5 \%$ when the $\mathrm{NaHSO}_{3}$ dosage was increased from $3 \%$ to $8 \%$. Sulfonation of lignin occurred during bisulfite pretreatment, which could be attributed to the sulfonation of $\mathrm{C} \alpha$ and/or $C \gamma$ in the phenyl-propane unit of lignin (Zhan 2009). The sulfonation of lignin could enhance the hydrophilicity of lignin, resulting in the dissolution of lignin during bisulfite pretreatment. Furthermore, it was found that the glucan loss was less than $6 \%$ when the $\mathrm{NaHSO}_{3}$ dosage was within the range of 3 to $8 \%$, indicating that most of cellulose in CS remained as solid during bisulfite pretreatment. 
Table 2. Chemical Components of Pretreated Corn Stover from Bisulfite Pretreatment

\begin{tabular}{|c|c|c|c|c|c|c|}
\hline $\begin{array}{c}\mathrm{NaHSO}_{3} \\
\text { dosage (\%) * }\end{array}$ & $\mathrm{pH}$ & $\begin{array}{l}\text { Yield } \\
(\%)\end{array}$ & $\begin{array}{c}\text { Extractives } \\
(\%)\end{array}$ & $\begin{array}{l}\text { Glucan (\%) } \\
\left(\% \text { loss }{ }^{\star *}\right)\end{array}$ & $\begin{array}{l}\text { Xylan }(\%) \\
\left(\% \text { loss }{ }^{* *}\right)\end{array}$ & $\begin{array}{l}\text { Total lignin }(\%) \\
\left(\% \text { loss }^{\star *}\right)\end{array}$ \\
\hline $\begin{array}{c}\text { Untreated } \\
\text { EFB }\end{array}$ & - & - & $2.29 \pm 0.20$ & $27.0 \pm 1.11$ & $13.02 \pm 0.62$ & $19.85 \pm 0.91$ \\
\hline 3 & 1.85 & 62.71 & $8.97 \pm 0.40$ & $\begin{array}{c}40.59 \pm 1.81 \\
(5.78)\end{array}$ & $\begin{array}{c}7.02 \pm 0.50 \\
(66.19)\end{array}$ & $\begin{array}{c}25.98 \pm 1.21 \\
(17.93)\end{array}$ \\
\hline 4 & 1.93 & 59.30 & $10.12 \pm 0.11$ & $\begin{array}{c}44.32 \pm 1.50 \\
(2.70)\end{array}$ & $\begin{array}{c}6.38 \pm 0.41 \\
(70.93)\end{array}$ & $\begin{array}{c}27.12 \pm 1.40 \\
(18.97)\end{array}$ \\
\hline 7 & 2.14 & 53.87 & $10.80 \pm 0.32$ & $\begin{array}{c}48.72+1.31 \\
(2.85)\end{array}$ & $\begin{array}{c}6.25 \pm 0.80 \\
(74.12)\end{array}$ & $\begin{array}{c}24.21 \pm 1.81 \\
(34.31)\end{array}$ \\
\hline 8 & 2.18 & 53.67 & $10.19 \pm 0.53$ & $\begin{array}{c}48.67 \pm 1.22 \\
(3.30)\end{array}$ & $\begin{array}{c}5.87 \pm 0.52 \\
(75.80)\end{array}$ & $\begin{array}{c}22.37 \pm 1.01 \\
(39.51)\end{array}$ \\
\hline
\end{tabular}

\section{Fermentability of Bisulfate-pretreated and Enzymatically Hydrolyzed CS}

Figure 1(a) shows the enzymatic digestibility of untreated and bisulfate-pretreated samples. The untreated CS exhibited a poor cellulose digestibility, which could only reach about $30 \%$ after $48 \mathrm{~h}$ of enzymatic hydrolysis. The enzymatic cellulose conversion of the pretreated cellulosic solids was increased with the increase of $\mathrm{NaHSO}_{3}$ dosage. After pretreatment with $3 \% \mathrm{NaHSO}_{3}$ and $1 \% \mathrm{H}_{2} \mathrm{SO}_{4}$, the enzymatic cellulose conversion was $65.6 \%$ with a cellulase dosage of $10 \mathrm{FPU} / \mathrm{g}$ dry sample after $48 \mathrm{~h}$ enzymatic hydrolysis (Fig. 1a). In the bisulfite pretreatment with $7 \%$ or $8 \% \mathrm{NaHSO}_{3}$, the conversion of cellulose could reach $85.9 \%$ and $86.0 \%$, respectively. In this experiment, a $\mathrm{NaHSO}_{3}$ dosage of $7 \%$ might be suitable for the CS bisulfite pretreatment due to the low chemical dosage and high cellulose conversion. In addition, the xylan conversion was higher than $85 \%$ when the cellulosic solid was hydrolyzed for $48 \mathrm{~h}$.

Under the bisulfite pretreatment conditions of $7 \% \mathrm{NaHSO}_{3}$ and $1 \% \mathrm{H}_{2} \mathrm{SO}_{4}$, the yield of the cellulosic solids was $53.9 \%$ based on the oven dry weight of untreated CS. The cellulosic solids of pretreated CS were used to produce bioethanol by Q-SSF at a solid concentration of 15\%. Figure 1(b) shows that the ethanol production was enhanced to 29 $\mathrm{g} / \mathrm{L}$ after $24 \mathrm{~h}$ of fermentation. The cellulose conversion was about $70 \%$, and the ethanol productivity was about $1.229 \mathrm{~g} / \mathrm{L} / \mathrm{h}$. In the system, the ethanol production was elevated to $36 \mathrm{~g} / \mathrm{L}$ after $48 \mathrm{~h}$ of fermentation. The cellulose conversion was about $86 \%$, and the ethanol productivity was about $0.752 \mathrm{~g} / \mathrm{L} / \mathrm{h}$. After $72 \mathrm{~h}$ fermentation, the ethanol production reached about $37 \mathrm{~g} / \mathrm{L}$. However, the ethanol productivity from the Q-SSF of pretreated EFB became $0.514 \mathrm{~g} / \mathrm{L} / \mathrm{h}$ at $72 \mathrm{~h}$, which was less than that at $24 \mathrm{~h}$ and $48 \mathrm{~h}$. Saha et al. (2013) have reached an ethanol concentration of about $21 \mathrm{~g} / \mathrm{L}$ and an ethanol productivity of about $0.29 \mathrm{~g} / \mathrm{L} / \mathrm{h}$ by using hydrothermally pretreated CS. Cai et al. (2016) have used a combinative technology of alkali and N-methylmorpholine-N-oxide (NMMO) to pretreat $\mathrm{CS}$ in order to improve the ethanol fermentation. The fermentation of the pretreated CS resulted in an ethanol yield of $64.6 \%$ through the separate hydrolysis and fermentation process, while it was only $18.8 \%$ for untreated samples with the cellulase loading of 15 FPU/g substrate. The results indicated that bisulfite pretreatment was an effective method 
for improving enzymatic hydrolysis of CS even at a low cellulase loading, by which a high conversion of cellulose to ethanol could be achieved.

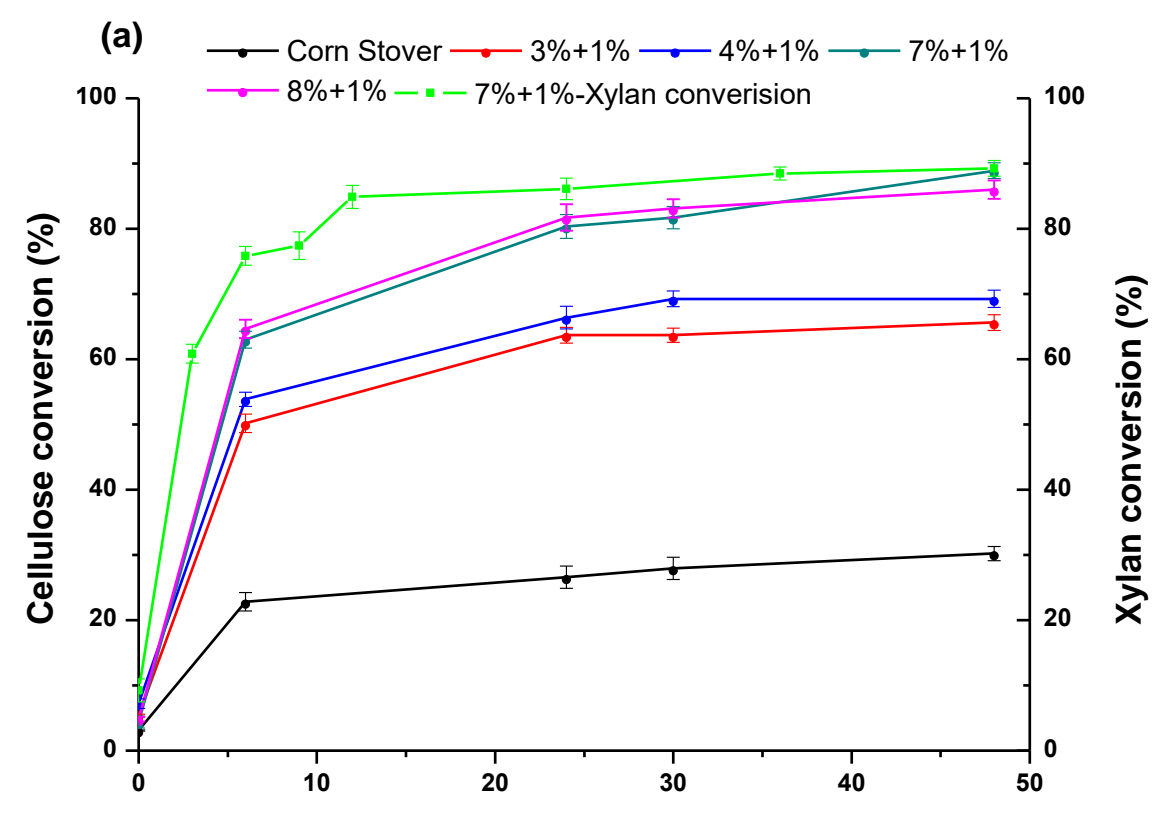

Hydrolysis time (h)

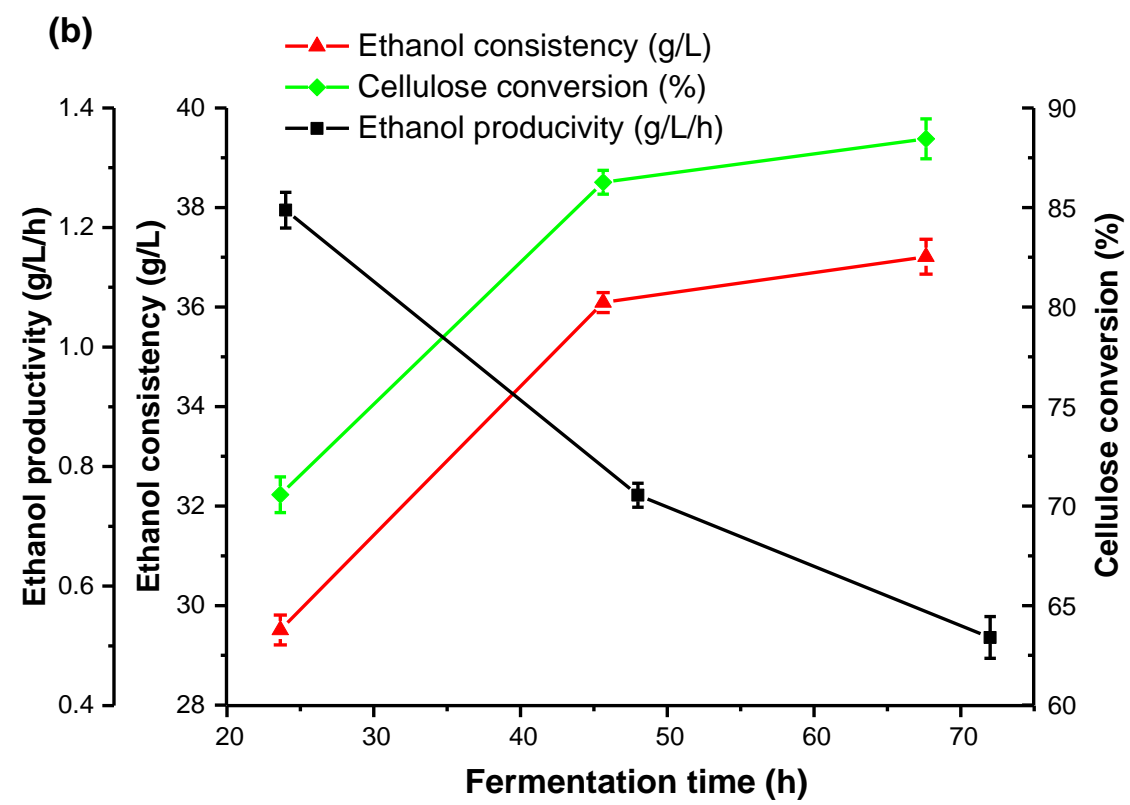

Fig. 1. Enzymatic digestibility (a) and ethanol productivity during Q-SSF (b) of bisulfite pretreated corn stover. (a) $2 \%$ solid concentration (dry matter basis), $\mathrm{pH}$ of 4.8 ( $0.05 \mathrm{M}$ sodium acetate buffer), $48^{\circ} \mathrm{C}, 150 \mathrm{rpm}$ in a shaker, and cellulase dosage of $10 \mathrm{FPU} / \mathrm{g}$ dry sample. (b) The solid concentration of Q-SSF was 15\%. Q-SSF process consisted of pre-hydrolysis and subsequent fermentation process. Cellic $\AA_{\text {CTec2 }}$ (cellulase loading of $10 \mathrm{FPU} / \mathrm{g}$ dry solid sample) was added in the pre-hydrolysis phase, followed by incubation for $6 \mathrm{~h}$. 


\section{Resin Separation for Fractionation of Spent Bisulfite Pretreatment Liquid and Preliminary Mass Balance of the Biorefinery Process}

Chemical components of spent bisulfite pretreatment liquid

In order to progressively improve the effective utilization of spent bisulfite pretreatment liquid, the major chemical components of the spent liquor were analyzed (including glucose, xylose, and lignin) (Table 3). It was found that the increase in $\mathrm{NaHSO}_{3}$ (from $3 \%$ to $8 \%, \mathrm{w} / \mathrm{w}$ ) could remove more xylose and lignin from bisulfite pretreatment at an $\mathrm{H}_{2} \mathrm{SO}_{4}$ dosage of $1 \%(\mathrm{w} / \mathrm{w})$. The concentrations of xylose and lignin in the spent bisulfite pretreatment liquid were about $6.75 \mathrm{~g} / \mathrm{L}$ and $9.52 \mathrm{~g} / \mathrm{L}$, respectively, when pretreatment was conducted with $3 \%$ bisulfite and $1 \%$ sulfuric acid. However, the concentrations of xylose and lignin were about $10.10 \mathrm{~g} / \mathrm{L}$ and $14.50 \mathrm{~g} / \mathrm{L}$, respectively, when the pretreatment was conducted with $7 \%$ bisulfite and $1 \%$ sulfuric acid. The concentrations of major chemical components existing in the bisulfite pretreatment liquid were obtained, which were consistent with the chemical components of the cellulosic solids.

Furthermore, the contents of furfural and 5-HMF were determined, since these are known to be the major fermentation inhibitors in the spent bisulfite pretreatment liquid (Table 3). 5-HMF is derived from the dehydration of glucose, and furfural is formed from the dehydration of xylose during sugar degradation by thermal acid (Larsson et al. 1999). These compounds, which inhibit the ethanol production by the yeast, are designated as fermentation inhibitors. The formation of furfural and 5-HMF was dependent on the combined effect of $\mathrm{NaHSO}_{3}$ dosage and acid dosage (Tan et al. 2016). Table 3 reveals that the increase of $\mathrm{NaHSO}_{3}$ dosage resulted in the increased furfural and 5-HMF concentrations in the spent liquor. These data suggested that the concentrations of furfural and 5-HMF in the spent liquor were $10.22 \mathrm{~g} / \mathrm{L}$ and $3.11 \mathrm{~g} / \mathrm{L}$ after bisulfite pretreatment, respectively, when using $7 \%$ bisulfite and $1 \%$ sulfuric acid.

Table 3. Concentrations of Major Chemical Components and Fermentation Inhibitors in Bisulfite Pretreatment Liquid

\begin{tabular}{|c|c|c|c|c|c|}
\hline $\begin{array}{c}\mathrm{NaHSO}_{3} \\
\text { dosage (\%) }\end{array}$ & $\begin{array}{c}\mathrm{H}_{2} \mathrm{SO}_{4} \\
\text { dosage (\%) }\end{array}$ & $\begin{array}{c}\text { Xylose } \\
\text { (g/L) }\end{array}$ & $\begin{array}{l}\text { Lignin } \\
(\mathrm{g} / \mathrm{L})\end{array}$ & $\begin{array}{c}\text { Furfural } \\
(\mathrm{g} / \mathrm{L})\end{array}$ & $\begin{array}{c}\text { 5-HMF } \\
(\mathrm{g} / \mathrm{L})\end{array}$ \\
\hline 3 & 1 & $6.75 \pm 0.21$ & $9.52 \pm 0.30$ & $9.21 \pm 0.20$ & $1.61 \pm 0.19$ \\
\hline 4 & 1 & $9.31 \pm 0.30$ & $10.32 \pm 0.11$ & $9.79 \pm 0.44$ & $2.48 \pm 0.11$ \\
\hline 7 & 1 & $10.10 \pm 0.51$ & $14.50 \pm 0.21$ & $10.22 \pm 0.51$ & $3.11 \pm 0.20$ \\
\hline 8 & 1 & $9.49 \pm 0.40$ & $14.73 \pm 0.10$ & $10.53 \pm 0.20$ & $2.67 \pm 0.32$ \\
\hline
\end{tabular}

\section{Resin separation}

The carbohydrate and lignin components in spent bisulfite pretreatment liquor were separated using four types of macroporous adsorption resin and $95 \%$ methanol as eluent. Figure 2A shows that the color of CCS was much lighter than that of pretreatment liquor, especially for the CCS under AB-8 separation. The recovery efficiencies of the carbohydrate and lignin components using different resins are listed in Fig. 2B-2C. Figure $2 \mathrm{~B}$ reveals that the recovery efficiencies of the reducing sugar in CCS from the chromatographic column with macroporous adsorption resins AB-8 and CAD-40 were higher (over 80\%) compared with DM130 and DM301. 
Moreover, the recoveries of reducing sugar using resin AB-8 were above $90 \%$. The lignosulfonate content in CCS was approximately 10\%, 19\%, 27\%, and 41\% when using resins AB-8, DM 130, DM 301, and CAD-40, respectively. In addition, resin AB-8 had higher efficiency in removing lignin components in CCS compared with other resins because of the higher carbohydrate content (above 90\%) and the lower lignosulfonate content (only about $10 \%$ of recovery of lignosulfonate). Besides, the eluent, named as LCS, was also analyzed (Fig. 2C). Recovery efficiencies of lignosulfonate in LCS were approximately $86 \%, 81 \%, 63 \%$, and $56 \%$ for resins AB-8, DM 301, DM 130, and CAD40 , respectively, whereas the recovery efficiencies of reducing sugar in LCS were all below $10 \%$. AB-8 resin was able to effectively separate the sugar and lignosulfonate components in the bisulfite pretreatment liquor based on these results. Therefore, the resin AB-8 might be selected for separating the carbohydrate and lignosulfonate constituents in the spent bisulfite pretreatment liquor. The authors' previous work has shown that the effective separation of spent bisulfite pretreatment liquid of empty fruit bunch from oil palm can be achieved by using the resin DM130, while this work revealed that the resin AB-8 was the best choice. This discrepancy might be caused by the different chemical compositions of the cell wall polymers (cellulose, hemicelluloses, and lignin) in different plant cell walls (Demartini et al. 2013).
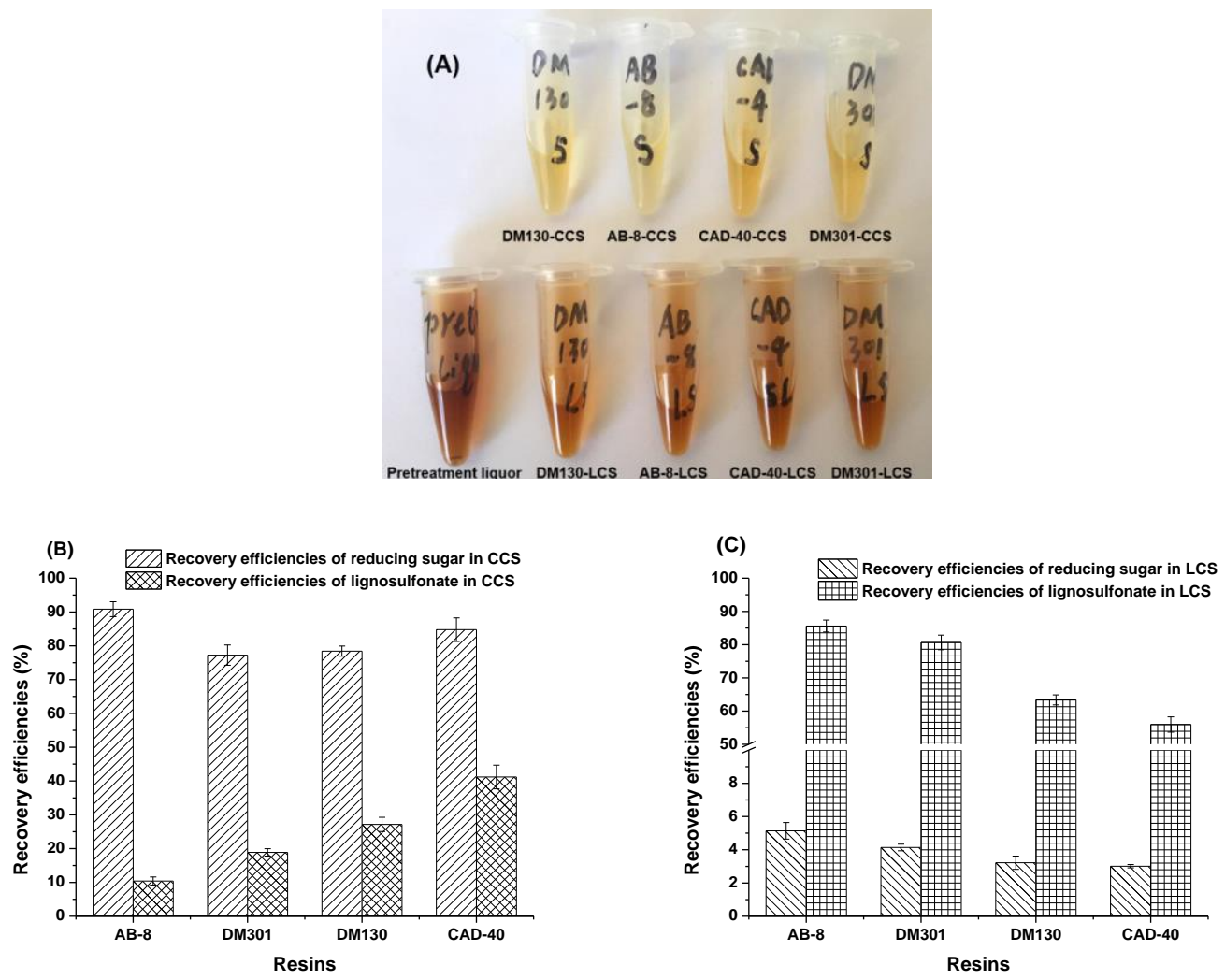

Fig. 2. (A) Photograph of carbohydrate constituent (CCS) and lignosulfonate constituent (LCS) by resin separation of the spent pretreatment liquid; (B) Recovery efficiencies of different constituents in CCS; (C) Recovery efficiencies of different constituents in LCS using different resins 


\section{Preliminary mass balance of the biorefinery process}

Figure 3 shows the preliminary mass balance of the overall process under bisulfite pretreatment when the Q-SSF process was conducted with $15 \%$ solids and a cellulase loading of $10 \mathrm{FPU} / \mathrm{g}$ substance. As a result, the ethanol yield of $162 \mathrm{~L} /$ ton CS was achieved through Q-SSF of the solid substrate from bisulfite pretreatment. Moreover, the yields of the lignin and xylan in the spent liquor were 58 and $76 \mathrm{~kg}$, respectively, for $1,000 \mathrm{~kg}$ of CS. For biorefinery of CS, the lignin and xylose/xylan fractions in the spent liquor were separated to produce lignosulfonate and xylose/xylan products by resin separation (resin AB-8 and 95\% methanol system). Lignosulfonates and xylose/xylan products could be sold as a commodity for their characteristics.

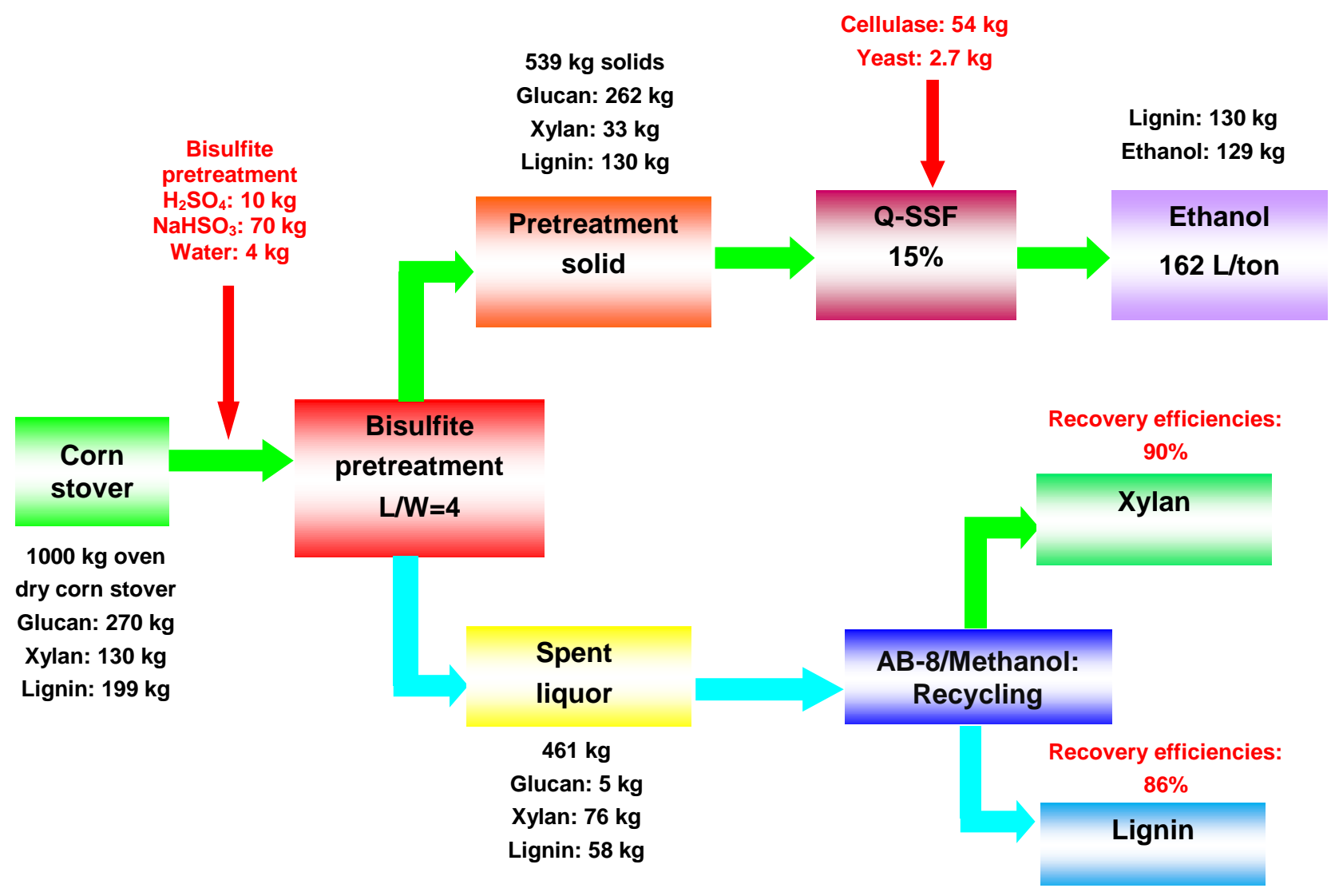

Fig. 3. Preliminary mass balance of biorefinery of corn stover with bisulfite pretreatment * pretreatment was conducted at $170{ }^{\circ} \mathrm{C}$ for $30 \mathrm{~min}$ with sodium bisulfite and sulfuric acid dosages of $7 \%$ and $1 \%$, respectively, on oven dry corn stover. Q-SSF was conducted at solid consistency of $15 \%$ and cellulase dosage of $10 \mathrm{FPU} / \mathrm{g}$ substrates

\section{Structure and Properties of LSS and WSS}

Figure 4 illustrates the FT-IR spectra of the LSS and WSS. LSS and WSS all contained functional groups, such as aromatic ring, alcoholic hydroxyl, methoxy, methyl, G-lignin, S-lignin, and other groups. The wide absorption around 3,404 to $3,410 \mathrm{~cm}^{-1}$ could be attributed to the $\mathrm{O}-\mathrm{H}$ stretching vibration in $-\mathrm{OH}$ groups, while the signals at $2,937 \mathrm{~cm}^{-1}$ could be assigned to the $\mathrm{C}-\mathrm{H}$ stretching vibrations in methyl groups. The bands at $1,517 \mathrm{~cm}^{-1}$ and $1,427 \mathrm{~cm}^{-1}$ corresponded to the aromatic ring vibrations. A small peak at $1,460 \mathrm{~cm}^{-1}$ corresponded to asymmetric $\mathrm{C}-\mathrm{H}$ deformations in $\mathrm{CH}_{3}$ and $\mathrm{CH}_{2}$. The vibrations caused by aliphatic $\mathrm{CH}$ stretching in $\mathrm{CH}_{3}$ at $1,384 \mathrm{~cm}^{-1}$ could be observed in the two spectra. The absorption peaks at $1,195 \mathrm{~cm}^{-1}$ were assigned to $\mathrm{C}-\mathrm{H}$ vibrations in methoxy 
groups. Absorptions of syringyl (S) units and guaiacyl (G) units were obviously observed at $1,123 \mathrm{~cm}^{-1}$ and $1,044 \mathrm{~cm}^{-1}$, respectively (Li et al. 2012). Certain changes were observed in LSS after separation when using resin AB-8 compared with WSS. The conjugated carboxyl absorption at $1,637 \mathrm{~cm}^{-1}$ was missing in the WSS spectra. In contrast, the band at $1,664 \mathrm{~cm}^{-1}$ due to $\mathrm{C}=\mathrm{O}$ stretch of conjugated $p$-substituted aryl ketones was observed in the LSS spectra. The signal at $1,246 \mathrm{~cm}^{-1}$ which was assigned to $\mathrm{C}-\mathrm{O}$ stretching vibrations in syringyl groups was much more prominent in LSS compared with WSS.

The sulfur content of WSS and LSS was determined using elemental analysis method. The contents of C, H, S, and N in WSS were $33.91 \%, 4.89 \%, 5.34 \%$, and $1.49 \%$, respectively, while those values became $49.08 \%, 6.01 \%, 2.88 \%$ and $2.41 \%$ in LSS, respectively. The results indicated that both LSS and WSS contained relatively high contents of sulfur. The decrease of sulfur content in LSS might be due to the removal of inorganic sulfur in WSS during resin separation, suggesting that lignin was better purified after resin separation (Tan et al. 2016). These results showed that LSS obtained from the spent bisulfite pretreatment liquor of CS was pure, and it consisted of relatively high content of sulfur, implying that LSS could be used as surfactants, chemical products, or in other industrial applications.

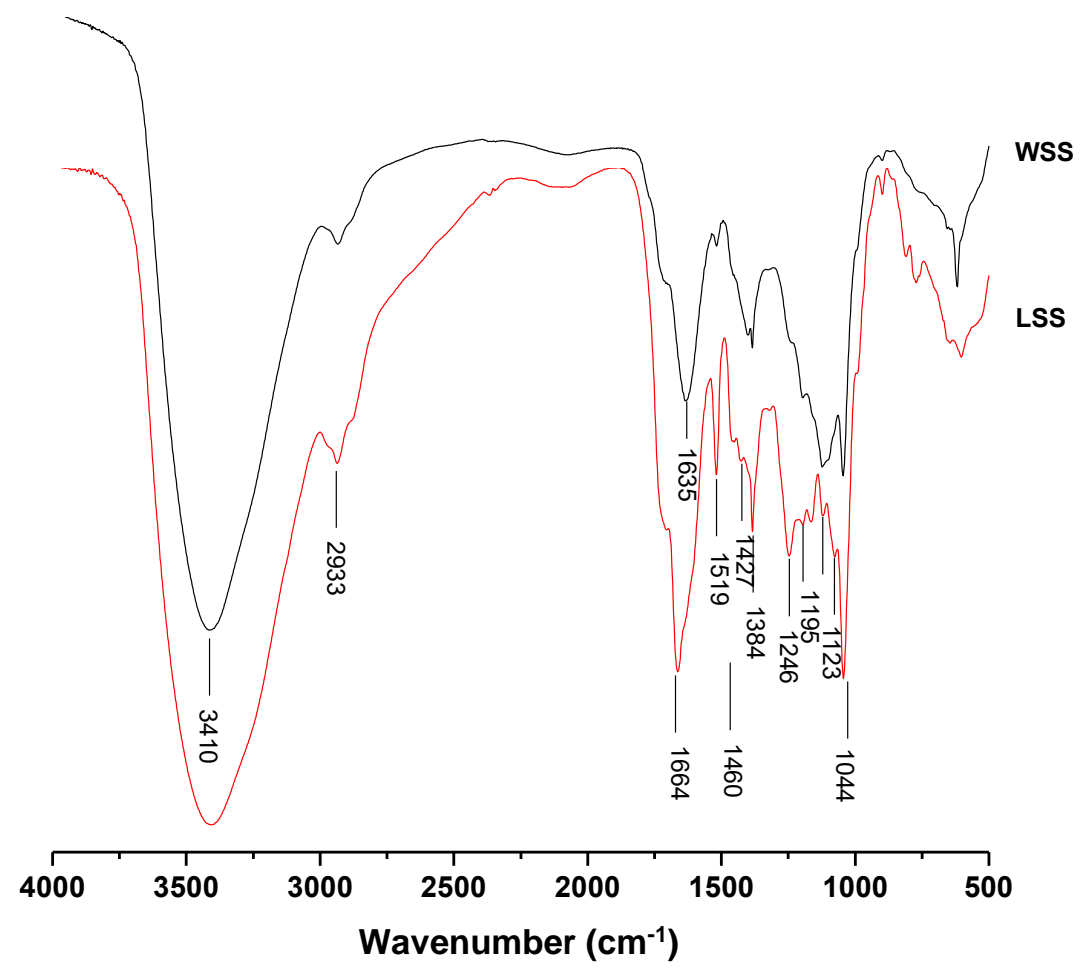

Fig. 4. FT-IR spectra of water-soluble substances in bisulfite pretreatment liquid (WSS) and lignosulfonate solids after resin separation (LSS)

\section{CONCLUSIONS}

1. Corn stover (CS) was fractionated into cellulosic solids, hemicellulosic sugars, and lignosulfonates following application of bisulfite pretreatment. 
2. The cellulosic solids were transformed into bioethanol by a quasi-simultaneous saccharification and fermentation (Q-SSF) process. The bisulfite pretreatment liquid was effectively separated into hemicellulosic sugars and lignosulfonates with the macroporous adsorption resin AB-8 and a 95\% methanol system.

3. The resulting lignosulfonate was pure, and it contained relatively high content of sulfur, suggesting that the lignosulfonate could be used as a surfactant or in other industrial applications.

\section{ACKNOWLEDGMENTS}

This study was supported by Natural Science Foundation of Shandong Province (Grant No. ZR2017LC015).

\section{REFERENCES CITED}

Aditiya, H. B., Mahlia, T. M. I., Chong, W. T., Nur, H., and Sebayang, A. H. (2016). "Second generation bioethanol production: A critical review," Renewable and Sustainable Energy Reviews 66, 631-653. DOI: 10.1016/j.rser.2016.07.015

Alvira, P., Tomáspejó, E., Ballesteros, M., and Negro, M. J. (2010). "Pretreatment technologies for an efficient bioethanol production process based on enzymatic hydrolysis: a review," Bioresource Technology 101(13), 4851-4861. DOI: 10.1016/j.biortech.2009.11.093

Breuil, C., and Saddler, J. N. (1985). "Comparison of the 3,5-dinitrosalicylic acid and Nelson-Somogyi methods of assaying for reducing sugars and determining cellulase activity," Enzyme and Microbial Technology 7(7), 327-332. DOI: 10.1016/01410229(85)90111-5

Brodeur, G., Yau, E., Badal, K., Collier, J., Ramachandran, K. B., and Ramakrishnan, S. (2011). "Chemical and physicochemical pretreatment of lignocellulosic biomass: A review," Enzyme Research (4999), 1-17. DOI: 10.4061/2011/787532

Buruiana, C.T., Vizireanu, C., Garrote, G., and Parajó, J. C. (2014). “Optimization of corn stover biorefinery for coproduction of oligomers and second generation bioethanol using non-isothermal autohydrolysis," Industrial Crops and Products 54(2), 32-39. DOI: 10.1016/j.indcrop.2014.01.003

Cai, L. Y., Ma, Y. L., Ma, X. X., and Lv, J. M. (2016). "Improvement of enzymatic hydrolysis and ethanol production from corn stalk by alkali and N-methylmorpholineN-oxide pretreatments," Bioresource Technology 212, 42-46. DOI: 10.1016/j.biortech.2016.04.012

Chen, H. Z., and Fu, X. G. (2016). "Industrial technologies for bioethanol production from lignocellulosic biomass," Renewable and Sustainable Energy Reviews 57, 468478. DOI: 10.1016/j.rser.2015.12.069

Dai, Q. Z., Jameel, H., and Chang, H. M. (2006). "Precipitation of extractives onto kraft pulps during black liquor recycling in extended delignification process," Journal of Wood Chemistry and Technology 26(1), 35-51. DOI: 10.1080/02773810600582210

Demartini, J. D., Pattathil, S., Miller, J. S., Li, H. J., Hahn, M. G., and Wyman, C. E. (2013). "Investigating plant cell wall components that affect biomass recalcitrance in 
poplar and switchgrass," Energy and Environmental Science 6(3), 898-909. DOI: $10.1039 / \mathrm{c} 3 \mathrm{ee} 23801 \mathrm{f}$

Dowe, N., and McMillan, J. (2008). "SSF experimental protocols-lignocellulosic biomass hydrolysis and fermentation," Laboratory Analytical Procedure (LAP), Technical Report, National Renewable Energy Laboratory /TP-510-42630.

Huang, K. X., Luo, J., Cao, R., Su, Y., and Xu, Y. (2018). "Enhanced xylooligosaccharides yields and enzymatic hydrolyzability of cellulose using acetic acid catalysis of poplar sawdust," J. Wood Chem. Technol. 38(5), 371-384. DOI: 10.1080/02773813.2018.1500608

Ho, M. C., Ong, V. Z., and Wu, T. Y. (2019). "Potential use of alkaline hydrogen peroxide in lignocellulosic biomass pretreatment and valorization - A review," Renewable and Sustainable Energy Reviews 112, 78-86.

Kadam, K. L., Chin, C. Y., and Brown. L. W. (2008). "Flexible biorefinery for producing fermentation sugars, lignin and pulp from corn stover," Journal of Industrial Microbiology and Biotechnology 35(5), 331-341. DOI: 10.1007/s10295-008-0322-0

Koljonen, K., Österberg, M., Kleen, M., Fuhrmann, A., and Stenius, P. (2004). "Precipitation of lignin and extractives on kraft pulp: effect on surface chemistry, surface morphology and paper strength," Cellulose 11(2), 209-224. DOI: 10.1023/b:cell.0000025424.90845.c3

Kumar, R., Mago, G., Balan, V., and Wyman, C. E. (2009). "Physical and chemical characterizations of corn stover and poplar solids resulting from leading pretreatment technologies," Bioresource Technology 99(17), 3948-3962. DOI: 10.1016/j.biortech.2009.01.075

Larsson, S., Palmqvist, E., Hahn-Hagerdal, B., Tengborg, C., Stenberg, K., Zacchi, G., and Nilvebrant, N. O. (1999). "The generation of inhibitors during dilute acid hydrolysis of softwood," Enzyme and Microbial Technology 24, 151-159. DOI: 10.1016/s0141-0229(98)00101-X

Li, H. Q., Jiang, W., Jia, J. X., and Xu, J. (2014). “pH pre-corrected liquid hot water pretreatment on corn stover with high hemicellulose recovery and low inhibitors formation," Bioresource Technology 153(1), 292-299. DOI: 10.1016/j.biortech.2013.11.089

Li, M. F., Sun, S. N., Xu, F., and Sun, R. C. (2012). "Formic acid based organosolv pulping of bamboo (Phyllostachys acuta): Comparative characterization of the dissolved lignins with milled wood lignin," Chemical Engineering Journal 179(4), 80-89. DOI: 10.1016/j.cej.2011.10.060

Li, Z., Jiang, Z., Fei, B., Cai, Z. Y., and Pan, X. J. (2014). “Comparison of bamboo green, timber and yellow in sulfite, sulfuric acid and sodium hydroxide pretreatments for enzymatic saccharification," Bioresource Technology 151, 91-99. DOI: 10.1016/j.biortech.2013.10.060

Li, Z., Yu, Y., Sun, J., Li, D. M., Huang, Y. D., and Feng, W. J. (2015). “Effect of extractives on digestibility of cellulose in corn stover with liquid hot water pretreatment," BioResources 11(1), 54-70. DOI: 10.15376/biores.11.1.54-70

Liu, Q., Li, W., Ma, Q., An, S. X., Li, M. H., Jameel, H., and Chang, H. M. (2016). "Pretreatment of corn stover for sugar production using a two-stage dilute acid followed by wet-milling pretreatment process," Bioresource Technology 211, 435442. DOI: 10.1016/j.biortech.2016.03.131

Liu, Z. H., Qin, L., Jin, M. J., Pang, F., Li, B. Z., Kang, Y., Dale, B. E., and Yuan, Y. J. (2013). "Evaluation of storage methods for the conversion of corn stover biomass to 
sugars based on steam explosion pretreatment," Bioresource Technology 132(2), 515. DOI: 10.1016/j.biortech.2013.01.016

Liu, Z.J., Lan, T.Q., Li, H., Gao, X., and Zhang, H. (2017). "Effect of bisulfite treatment on composition, structure, enzymatic hydrolysis and cellulase adsorption profiles of sugarcane bagasse," Bioresource Technology 223, 27-33. DOI:

10.1016/j.biortech.2016.10.029

Loow, Y. L., Wu, T. Y., Yang, G. H., Ang, L. Y., New, E. K., Siow, L. F., Jahim, J. M., Mohammad, A. W., and Teoh, W. H. (2018). "Deep eutectic solvent and inorganic salt pretreatment of lignocellulosic biomass for improving xylose recovery," Bioresource Technology 249, 818-825. DOI: 10.1016/j.biortech.2017.07.165

Meng, X., Sun, Q., Kosa, M., and Huang, F. (2016). "Physicochemical structural changes of poplar and switchgrass during biomass pretreatment and enzymatic hydrolysis," Acs Sustainable Chemistry and Engineering 2016, 4(9), A-J. DOI: 10.1021/acssuschemeng.6b00603

Milano, J., Ong, H. C., Masjuki, H. H., Chong, W. T., Lam, M. K., Loh, P. K., and Vellayan, V. (2016). "Microalgae biofuels as an alternative to fossil fuel for power generation," Renewable and Sustainable Energy Reviews 58, 180-197. DOI: 10.1016/j.rser.2015.12.150

Papa, G., Feldman, T., Sale, K. L., Adani, F., Singh, S., and Simmons, B. A. (2017). "Parametric study for the optimization of ionic liquid pretreatment of corn stover," Bioresource Technology 241, 627-637. DOI: 10.1016/j.biortech.2017.05.167

Saha, B. C., Yoshida, T., Cotta, M. A, and Sonomoto, A. (2013). "Hydrothermal pretreatment and enzymatic saccharification of corn stover for efficient ethanol production," Industrial Crops and Products 44(2), 367-372. DOI:

10.1016/j.indcrop.2012.11.025

Sluiter, A., Hames B., Ruiz R., Scarlata, C., Sluiter, J., Templeton, D., and Crocker, D. (2008). "Determination of structural carbohydrates and lignin in biomass," Laboratory Analytical Procedure 1617, 1-16.

Sundaram, V., Muthukumarappan, K., and Kamireddy, S. R. (2015). "Effect of ammonia fiber expansion $\left(\mathrm{AFEX}^{\mathrm{TM}}\right)$ pretreatment on compression behavior of corn stover, prairie cord grass and switchgrass," Industrial Crops and Products 74, 45-54. DOI: 10.1016/j.indcrop.2015.04.027

Tan, L. P., Yu, Y. C., Li, X. Z., Zhao, J., Qu, Y. B., Choo, Y. M., and Loh, S. K. (2013). "Pretreatment of empty fruit bunch from oil palm for fuel ethanol production and proposed biorefinery process," Bioresource Technology 135, 275-282. DOI: 10.1016/j.biortech.2012.10.134

Tan, L. P., Sun, W., Li, X. Z., Zhao, J., Qu, Y. B., Choo Y. M., and Loh, S. K. (2015). "Bisulfite pretreatment changes the structure and properties of oil palm empty fruit bunch to improve enzymatic hydrolysis and bioethanol production," Biotechnology Journal 10(6), 915-922. DOI: 10.1002/biot.201400733

Tan, L. P., Wang, M. M., Li, X. Z., Li, H. X., Zhao, J., Qu, Y. B., Choo Y. M., and Loh, S. K. (2016). "Fractionation of oil palm empty fruit bunch by bisulfite pretreatment for the production of bioethanol and high value products," Bioresource Technology 200, 572-578. DOI: 10.1016/j.biortech.2015.10.079

Tian, S., Zhu, W., Gleisner, R., Pan, X. J., and Zhu, J. Y. (2011). "Comparisons of SPORL and dilute acid pretreatments for sugar and ethanol productions from aspen," Biotechnology Progress 27(2), 419-427. DOI: 10.1002/btpr.545 
Uppugundla, N., Sousa, L. D. C., Chundawat, S. P., Yu, X. R., Simmons, B., Singh, S., Gao, X., Kumar, R., Wyman, C. E., Dale, B. E., and Balan, V. (2014). “A comparative study of ethanol production using dilute acid, ionic liquid and AFEX ${ }^{\mathrm{TM}}$ pretreated corn stover," Biotechnology for Biofuels 7(1), 1-14. DOI: 10.1186/17546834-7-72

Wang, G. S., Yu, M. H., and Zhu, J. Y. (2011). "Sulfite pretreatment (SPORL) for robust enzymatic saccharification of corn stalks," Advanced Materials Research 236-238, 173-177. DOI: 10.4028/www.scientific.net/AMR.236-238.173

Yu, H., Ren, J. W., Liu, L., Zheng, Z. J., Zhu, J. J., Yong, Q., and Ouyang, J. (2015). “A new magnesium bisulfite pretreatment (MBSP) development for bio-ethanol production from corn stover," Bioresource Technology 199, 188-193. DOI: 10.1016/j.biortech.2015.08.090

Zabed, H., Sahu, J. N., Boyce, A. N., and Faruq, G. (2016). "Fuel ethanol production from lignocellulosic biomass: An overview on feedstocks and technological approaches," Renewable and Sustainable Energy Reviews 66, 751-774. DOI: 10.1016/j.rser.2016.08.038

Zhan, H. Y. (2009). Pulping Principle and Engineering, China Light Industry Press, pp. 34-59.

Zhang, X., Yang, W., and Blasiak, W. (2011). "Modeling study of woody biomass: Interactions of cellulose, hemicellulose, and lignin," Energy and Fuels 25(10), 47864795. DOI: 10.1021/ef201097d

Zhao, X., Zhang, L., and Liu, D. (2012). "Biomass recalcitrance. Part I: The chemical compositions and physical structures affecting the enzymatic hydrolysis of lignocellulose," Biofuels Bioproducts and Biorefining 6(4), 465-482. DOI: 10.1002/bbb.1331

Zhu, J. Y., Pan, X. J., Wang, G. S., and Gleisner, R. (2009). "Sulfite pretreatment (SPORL) for robust enzymatic saccharification of spruce and red pine," Bioresource Technology 100(8), 2411-2418. DOI: 10.1016/j.biortech.2008.10.057

Article submitted: April 10, 2019; Peer review completed: June 16, 2019; Revised version received and accepted: June 21, 2019; Published: June 26, 2019.

DOI: 10.15376/biores.14.3.6501-6515 